Canadian Studies in Population, Vol. 30(1), 2003, pp. 137-158

\title{
Impact of "Ethnic Mobility" on Socio-economic Conditions of Aboriginal Peoples
}

\author{
Andrew J. Siggner \\ Senior Advisor on Aboriginal Statistics, \\ Housing, Family, \& Social Statistics Div., \\ Statistics Canada \\ Ottawa, Ontario, Canada
}

\begin{abstract}
For the first time data from the 1986 and 1996 censuses have been organized in an historical manner with a consistent set of definitions and geographies. Guimond (1999) has established that the Aboriginal population, both in terms of origin and identity, has grown rapidly and that an important component of that growth has come from personal changes in the ethnic affiliation. This finding begs the question: what are the characteristics of the people changing their affiliation? Using census data, this study will focus on the highest level of schooling variable for the populations reporting Aboriginal origins and Aboriginal identity and show how this characteristic is changing in a selected age cohort over the ten year period 1986-96.
\end{abstract}

Key Words: Aboriginal population, ethnic origin, aboriginal identity, ethnic mobility, education levels 
Andrew J. Siggner

\section{Résumé}

C'est la premiére fois que les données des recensements de 1986 et de 1996 ont été classes d'une manière historique avec un ensemble conforme de definitions et d'éléments géographiques. Guimond (1999) a établi que la population authochtone, autant en termes d'origine que d'identité, avait augmenté rapidemont et qu'une et qu'ne composante importante de cette croissance venait de changements personnels dans l'affiliatiion ethnique. Cette découverte soulève la question, à savoir quelles sont les caractéristiques d'un people qui change d'affiliation ? En se servant des donnés des recensements, cette etude examine le taux de scolarité le plus élevé variable des populations indiquant des origins ou une identité autochtones et démontre de quelle manière cette caractéristique change dans une cohorte d'âge sur une période de dix ans, soit de 1986 à 1996.

Mots-clés: population autochtone, origine ethnique, identité autochtone, ethnique mobilité, niveau d'éducation

\section{Introduction}

What is the link of the socio-economic conditions of Aboriginal peoples to the definition of Aboriginal peoples and their demographic behavior? Philip Kreager provides a salient justification when he states:

"For members of a given collectivity, from the family to the state, deciding who is and who is not included in the group generally determines its capacities. The estimated capacities of one group in comparison with others have a direct bearing on courses of action for all collectivities that may be implicated. The fact that people may report their ethnic, religious and other identities differently from one census to the next...to suit preferred statuses, is significant not only as a potential source of bias affecting the analysis of trends, but as evidence of active adjustment of population composition and structure to changing circumstances." Kreager [1997]

For the first time data from the1986 and 1996 censuses have been organized in an historical manner with a consistent set of definitions and geographies. Guimond (1999) has established that the Aboriginal population, both in terms of origin and identity, has grown rapidly and that an important component of that growth has come from personal changes in the ethnic affiliation. This finding begs the question: what are the characteristics of the people changing their affiliation? If we do not know more about the group or groups who 
ethnically have moved into the Aboriginal origin and identity populations, how can we rely on the aggregate Aboriginal statistics? How can policy-makers and planners really know what impact their policies and programs are having on the target populations?

Using census data, this study will focus on the highest level of schooling variable for the populations reporting Aboriginal origins and Aboriginal identity and show how this characteristic is changing in a selected age cohort over the ten year period 1986-96. The issue which Kreager raises on "deciding who is in the group and who is not" affects the determination of the capacities of the group, and this is fundamental to the analysis that follows. As will be observed, such a choice does affect the determination of the capacity of a given population and has important implications for decision makers.

Is there some guidance for the researchers to direct their choice on the operational definition of the Aboriginal population? The answer is, yes. The Royal Commission on Aboriginal Peoples provided some guidance on this choice when it decided to focus attention primarily on the Aboriginal population that self-identifies as such:

"According to the two most recently published data sources, the number of Aboriginal people in Canada in 1991 was between 626,000 and just over 1,000,000, depending on the definition and data source used. The 1991 census reported the latter figure, based on a question that determined cultural origins or ancestry, while the former figure resulted from a 1991 national survey of Aboriginal people known as the Aboriginal Peoples Survey (APS), also conducted by Statistics Canada. Unlike the census, this survey focused on those who identified with their Aboriginal ancestry. Both approaches to identifying the Aboriginal population have merit, but the Commission has relied primarily on the count of those who identify with their Aboriginal ancestry. It does so knowing that some portion of the 375,000 who do not do so now may well do so in the future." Royal Commission on Aboriginal Peoples (1996)

Nevertheless, because the data are now available in such a way as to allow us to examine the various combinations of those reporting Aboriginal origins and Aboriginal identity, we have chosen to analyze data along both dimensions.

\section{Highest Level of Schooling}

As the Aboriginal identity population builds its capacity to assume the demand for skilled jobs created by self-government and economic development, the obvious major supply for such capacity building will be its youth aged population and its contribution to the skill pool via the improvement in their educational attainment. However, as shall be observed below, there has been a growth in the numbers with higher levels of schooling among the older age 
Andrew J. Siggner

groups and it may not only be coming from the choice of these older individuals to go back to school in order to gain higher levels. The contribution to the skill levels may well be coming from those persons who more recently have chosen to report their Aboriginal origins and/or who self-identify with one of the Aboriginal groups, and who already are better-educated.

We examine the changes in the numbers and distribution by highest level of schooling using a cohort approach over a ten-year period. There are two main factors likely contributing to a shift in both the numbers and percentage distribution by highest level of schooling within the same age cohort which we follow over a ten year period. (The cohort which is followed is the one which is age $25+$ in 1986 and age $35+$ in 1996.)

- One factor is a better-educated ethnically mobile population entering the Aboriginal population; and

- the second factor comes from those Aboriginal persons already present in the cohort at the beginning of the period in 1986 who have gone back to school and gained more schooling over the tenyear period.

In order to demonstrate the impact of ethnic mobility and other factors on the change in educational attainment between 1986 and 1996 in the Aboriginal origin and Aboriginal identity populations, we adapt an approach used by Eschbach, Supple and Snipp (1998). They point out that ethnic boundaries are "assuming an ambiguity and fluidity", where membership in an ethnic category "is the outcome of a social process of identification" and no longer a fixed attribute. ${ }^{1}$ They found that in the United States, American Indians display this fluidity "because of the long history of intermarriage between American Indians and other groups, [such that, ethnic] identity for many American Indians involves a choice..." (Eschbach, et al. (1998).

The same phenomenon has occurred in Canada, where the Aboriginal populations, measured in terms of their origins and identity, have increased not only as a result of the contribution from natural increase and other demographic factors over the 1981-96 period, but also as a function of ethnic mobility. (Guimond, 1999) Given this trend, does the net influx of this new population bring with them different socio-economic characteristics?

One way to determine this is to use a cohort approach and follow the same age cohort over time and see if the numbers of persons and distribution at the same level of schooling has changed and in what direction. The Eschbach model hypothesizes that if there is an increase over time in the number of persons at a given level of schooling within same age cohort, the increase is likely due to changes in how the population is reporting its ethnic origins or identity, in addition to other factors. 
1. Aboriginal persons (as defined by origin or identity) in an age cohort at the beginning of the time period can gain more education because they are attending school and graduating over the observed time period.

2. Differences in age-specific mortality rates by education, which have been well-documented in the literature (Kitagawa and Hauser 1973; Mare, 1990; Nault, F., et al, 1996), and

3. Inflated reporting of educational attainment at later censuses (Farley 1968).

4. The American study also assumes that the factors in points 2 and 3 above affect all groups in society equally and thus, will not impact the educational distribution for an age cohort differentially.

The Eschbach et al model takes the American Indian population aged 25+ in 1970 by highest level of schooling category (less than Grade 9 up to those with $4+$ years of college) and survives each group to 1990, when they would be 45+ years old. Then, the authors compare the estimated survived cohort to the actual distribution from the 1990 Census. If there were more people in the actual distribution than in the survived cohort for a given level of schooling, the authors concluded, given their assumptions about the other factors, that:

"Census-enumerated American Indians who were at least 45 years old in 1990 had more education than these same cohorts when they were enumerated 20 years earlier." Eschbach et al. (1998)

Their data show that those with four or more years of college proportionately more than doubled over the twenty year period within the same cohort, even after adjusting for differential mortality among those with different levels of education. Based on this analysis, the authors conclude that "changes in identification [i.e. from 'non-Indian' to 'Indian'] are left to account for a net upward shift in educational attainment for American Indians."

\section{Method and Assumptions}

Turning to the Canadian data, we apply the Eschbach et al approach, but rather than applying survival rates to the Aboriginal populations aged $25+$, we make a more conservative assumption about mortality. It is assumed that there is no mortality to the cohort aged 25+ in 1986 as it ages to $35+$ in $1996 .^{2}$ If the difference between the actual cohort ages 35+ in 1996 and the original cohort is positive, it means that there was a net upward shift in the number of Aboriginal people in that age cohort for a specific category of schooling over the ten-year period. If the difference is negative, the cohort has experienced a net loss in a specific level of schooling. We measure the change in the age cohort by 
Andrew J. Siggner

calculating the average annual growth rates in the size of the cohort for each level of schooling.

The next step involves using the same age cohort for the total population of Canada as a benchmark for comparing its growth rates by level of schooling with those of the Aboriginal population. We first examine how the original cohort age 25+ for the total population of Canada in 1986 has changed by the time it reaches age $35+$ in 1996 . Because we are using the total population of Canada as a benchmark, changes in its cohort age 25+ in 1986 and 35+ in1996, by level of schooling, will not be the result of ethnic mobility. However, there are other factors that may affect a change in the cohort's size.

1. The main factor affecting the change in the size of this group's cohort is due to the improvement in educational attainment within the original cohort over the 10 -year period.

2. Another factor that may be affecting the change in the level of schooling distribution within the total population of Canada is the higher educational levels among net immigrants to Canada compared to the schooling attainment among their non-migrant counterparts. There is evidence that immigrants do affect the distribution by highest level of schooling. For example, in 1996 the share of recent immigrants aged 25-44 with a university degree was about $34 \%$, while among non-migrants it was about $19 \%$. The contribution of the immigrants resulted in the percentage of the total population of Canada with a university degree shifting up to about 21\%. (Statistics Canada (1998) Thus, for example, if there is an increase in the size of the cohort with a university degree over the ten years, some portion of it may be due to the net impact of better-educated immigrants. However, as we shall see in Table 1, the growth rates in the cohort for the total population of Canada by level of schooling is very low in comparison to those of the Aboriginal population (by origin or identity). If we removed the effects of the better-educated immigrants, the growth rates for the total population cohort would be even smaller.

3. The other factor is mortality within the cohort, although it is not expected to be significant.

By using the growth rates in the 25+ age cohort for the total population of Canada by highest level of schooling over the 1986-96 period as a benchmark, we then can compare them to the growth rates in the equivalent cohort in the population by Aboriginal origins and identity. We hypothesize is that if the growth rates by highest level of schooling for the Aboriginal cohorts are substantially higher than those of the total population's, then it is likely that changes in ethnic affiliation from non-Aboriginal to Aboriginal origin and/or identity are a major contributor to the observed growth. If the growth rates by level of schooling are not significantly different from or are lower than those of 


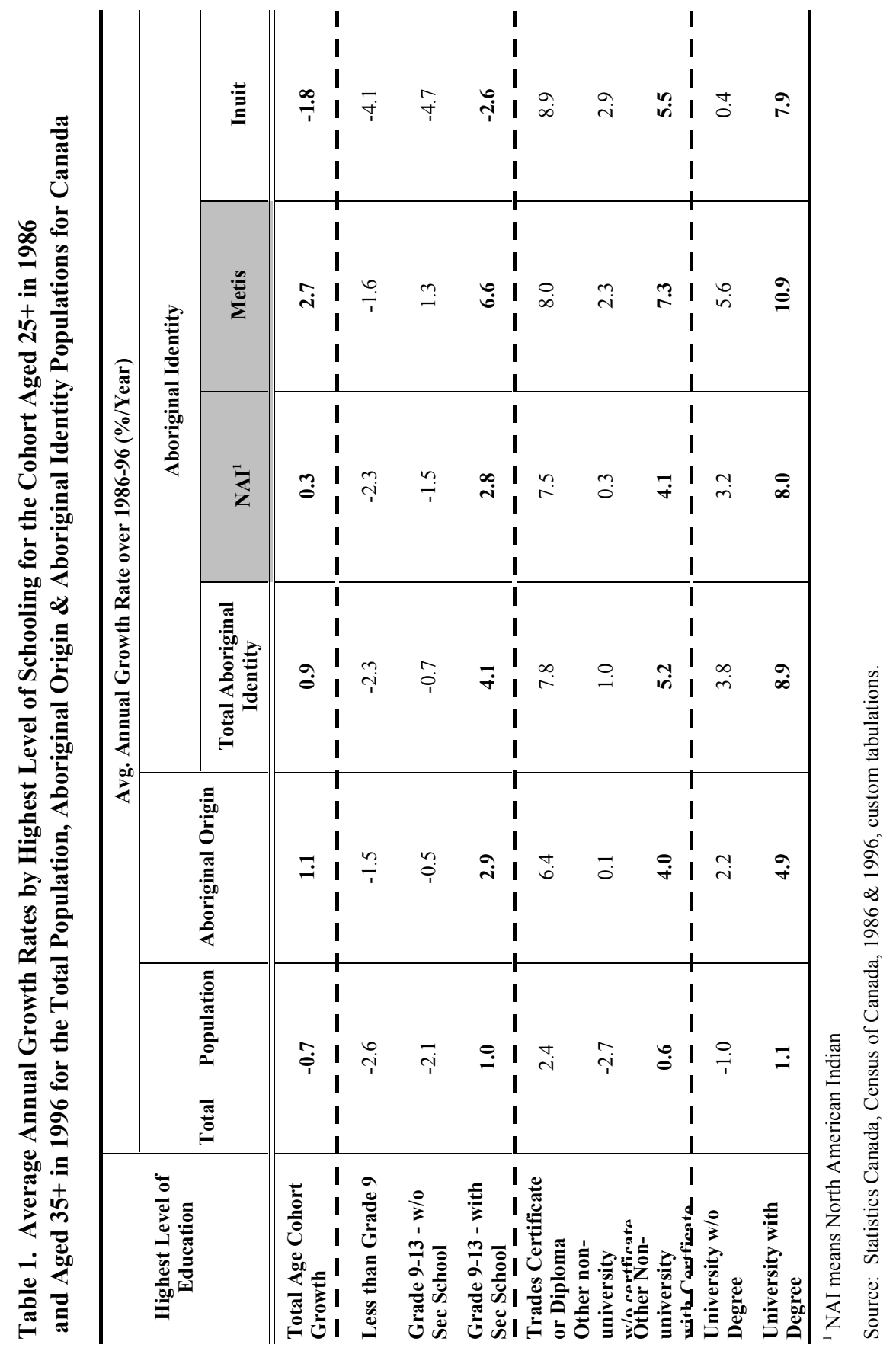


Andrew J. Siggner

the total population cohort, then it is likely that the Aboriginal growth rates are reflecting the improvement of schooling levels by the original cohort over the 1986-96 period.

The other factor affecting all the cohorts is mortality. For example, let us take the case of the cohort which increases in size within a specific schooling level. What ever deaths have occurred to the cohort when it reaches age 35+ in 1996, the number of deaths was not significant enough to overcome the net impact from ethnic mobility or the improvement in educational attainment by the original cohort during the previous ten years. In the case of the cohort, which decreases in size within a certain schooling level, it is likely the combination of mortality and improvement in educational attainment within the original cohort that is contributing to the decline, while the effect of net ethnic mobility at this level of schooling is not sufficient to offset the decline.

In regard to the improvement of educational attainment within the original cohort, Eschbach et al assumed that the original American Indian population cohorts were likely improving their educational attainment at the same rate over the time period as their counterparts in the general U.S. population. They conclude that any positive growth in the cohort at a given level of schooling is, therefore, attributed to ethnic mobility into the American Indian population. Can we make the same assumption for the Canadian situation?

We know that higher proportions of older Aboriginal persons are attending school, whether it is for high school equivalency or post-secondary schooling. (Tait, H., 1998) This is likely related to the fact there have been major government incentives over the 1986-96 period for Aboriginal peoples, in general, and registered Indians in particular, to improve their educational attainment levels. Such incentives would likely serve as an encouragement to the original cohort to improve its schooling levels. On the other hand, when the Indian Act was amended in 1985 under Bill C-31, it allowed over 100,000 people to regain their Indian status, thus also making them eligible for free postsecondary schooling. This certainly would have been a major incentive for people to declare their 'Aboriginality' on the census and in the 1991 Aboriginal Peoples Survey, if they had not done so before. The amendment also would serve as an incentive to declare one's Aboriginality for those who thought they may be eligible, even though in the end they may not have met the revised requirements of the Indian Act. Finally, another government incentive may have been at a factor. Employment equity legislation targets four groups in Canadian society: women, visible minorities, Aboriginal peoples, and the disabled population with the intent to improve their representation in the labour market.

Given these different types of incentives, our ability to disentangle these factors to determine exactly how much growth in the cohort is due to ethnic mobility is almost impossible with existing data. Ideally one would need a longitudinal survey which follows the same group of respondents over time on how they report their Aboriginality (by origins and identity) and relate that to other factors affecting their schooling levels, labour market activities, etc. 
Impact of "Ethnic Mobility" on Socio-economic Conditions

of Aboriginal Peoples

Before the results of the analysis are presented, a number of other assumptions are made.

1. The analysis is confined to the Canada level to exclude effects from the internal migration of Aboriginal peoples.

2. Since there is very little impact on the Aboriginal population from international migration, we assume a virtually closed population.

3. The effect of Census under coverage is not expected to be a major factor in the growth of the cohort, even though data for the Canadian population, as a whole, indicates that the younger end of the broad age groups, $25+$ and $35+$ tend to experience higher rates of under coverage than the older end of these age groups. The overall all impact on the growth rate of the cohort 25+ from 1986 to 1996 is relatively minor.

\section{Results: What do the Canadian Data Show?}

We begin the analysis by focusing on the cohort which is age 25+ in 1986 and 35+ in 1996 for the Aboriginal origin population, by highest level of schooling. This is followed by looking at those who self-identify with their Aboriginal origins and those who do not. Then, we examine the individual Aboriginal groups. Although we will examine the result for all highest level of schooling categories, we will focus on those with a university degree. It is this type of schooling where Aboriginal people tend to lag significantly behind their nonAboriginal counterparts and yet, capacity building is needed to meet the demand for jobs associated with Aboriginal self-government in the future. For example, in 1996, while nearly $14 \%$ of the Non-Aboriginal population age 15 and over had a university degree, $6 \%$ of the Aboriginal origin population did, and only $3.4 \%$ of the Aboriginal identity population (i.e. the subset of those with an Aboriginal origin(s) who also self-identify as an Aboriginal person) had a university degree - see Figure 1.

Following the Eschbach et al model, we hypothesize that among those with higher levels of schooling, the cohort age $35+$ reporting Aboriginal origins and Aboriginal identity in 1996 will be larger than when it was age 25+ ten years earlier. What we have found is that the Aboriginal origin cohorts with at least completed high school have positive average annual growth rates over the 198696 period - see Figure 2. At each level of schooling from completed high school to university degree, the average annual growth was at least three times higher than the growth rates for same age cohort and equivalent schooling levels within the total population of Canada. For example, for those with a university degree, the Aboriginal origin cohort had a growth rate of almost $5 \%$, which was nearly five times greater than that of the total population of Canada. For the cohort reporting Aboriginal identity, the growth rates for those with at least 

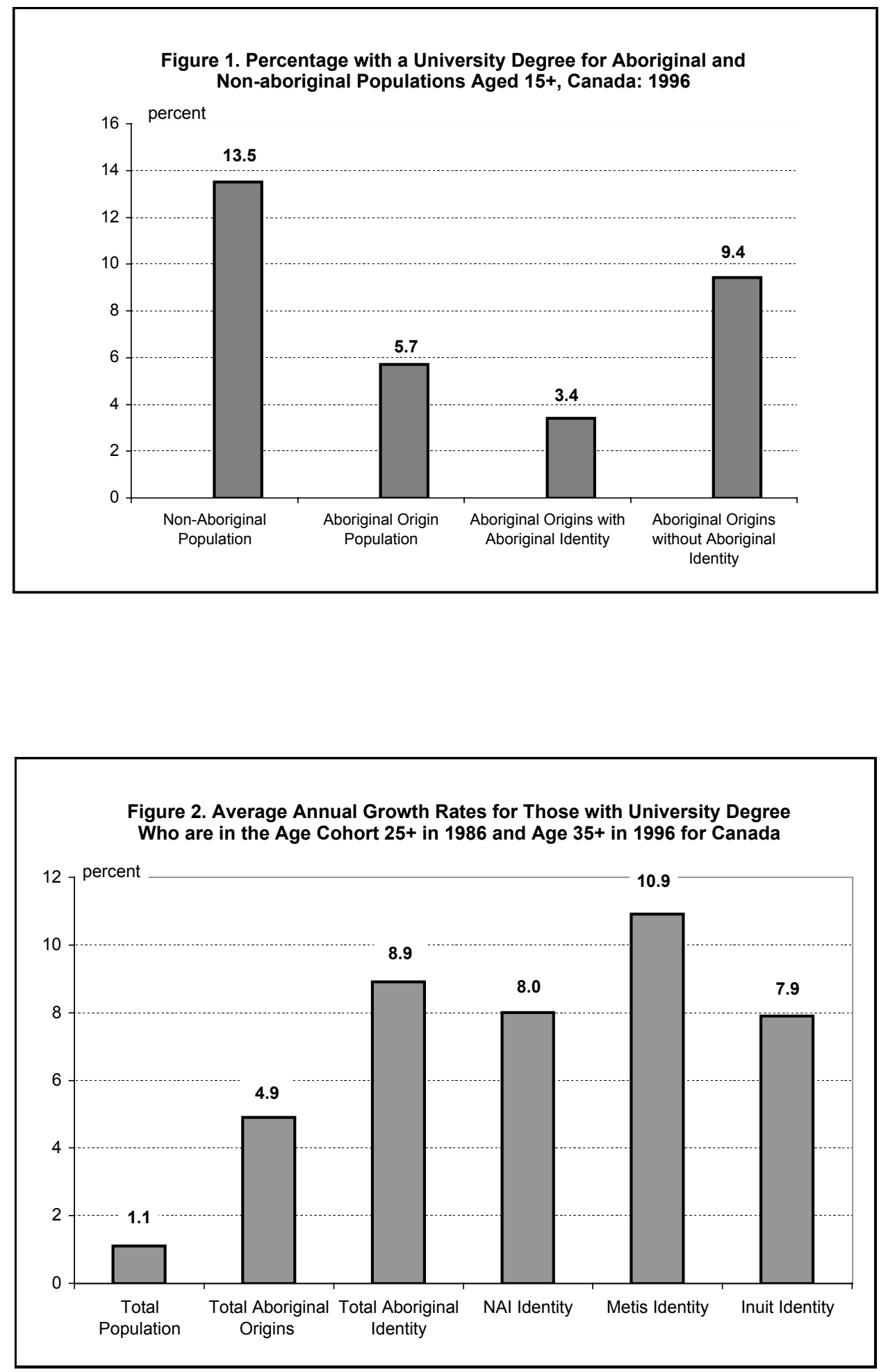
high school completion were even higher than for those in the Aboriginal origin population. For example, the growth in the cohort with a university degree was nearly $9 \%$ per year for the Aboriginal identity population, compared to the $1 \%$ per year average in the total population of Canada. Thus, even if we allowed that half of the growth in each of the Aboriginal origin and identity cohorts with university degrees was due to improved levels of educational attainment within these cohorts, it would still leave the other half of the growth due to ethnic mobility into the Aboriginal population by those with already high levels of schooling. Any mortality in the cohorts with these levels of schooling is not sufficient to overcome the positive growth due to the other two factors.

Among the individual Aboriginal identity groups, i.e. North American Indians, Metis, and Inuit, their respective cohort trends were similar to the overall Aboriginal identity cohort. However, the Metis identity group displays the highest average annual growths at the completed high school, other nonuniversity (community college) certificate and university degree levels, compared to the other two Aboriginal groups. It will be recalled from Chapter 4 , that it is the Metis which maintained an average annual population growth rate throughout the 1986-96 period which was above the theoretical maximum of $5.5 \%$ per year. We concluded that ethnic mobility was still a significant contributor to the demographic growth of Metis population over the 1991-96 period, while for the other two groups it was not. This may be why, for example, the average annual growth rate for the North American Indian cohort with a university degree is lower than the Metis'.

In contrast, those with less than completed high school had negative growth rates, that is, the actual size of the cohort age 35+ in 1996 is smaller than the size of the cohort when it was age 25+ in1986. At this lower end of the schooling continuum, the net effect (if there is any) of ethnic mobility on the actual 1996 cohort aged 35+ is likely outweighed by the loss to the actual cohort aged $35+$ due to mortality ${ }^{3}$ and to improvement in schooling levels within this cohort. From Table 1 we find that for both Aboriginal origin and identity population cohorts, those with less than completed high school and less than Grade 9 had negative growth rates as hypothesized - see Table 1. This was true of the non-Aboriginal population, as well. Interestingly, for the cohort reporting Aboriginal origins age 35+ in 1996 with less than a completed high school, their numbers dropped by about 15,000 over the ten years. On the other hand, this net loss is nearly offset by the net gain among those with a high school completion and trades certificates, which was about 14,400 - see Table 2. Eschbach et al also found this trend for the American Indian data among those with less than 12 years of high school (Eschbach et al, 1998, p.41). Although there is no assurance these are the same Aboriginal people increasing their schooling levels, government programs have been encouraging high school upgrading, especially for registered Indians.

Another important observation to be made from this table is that the gains in the cohort age 35+ in 1996 compared to the original cohort from 1986 at the higher levels of schooling far exceed the losses experienced at the lower levels of schooling. Over the ten years those with non-university certificates aged 35+ 


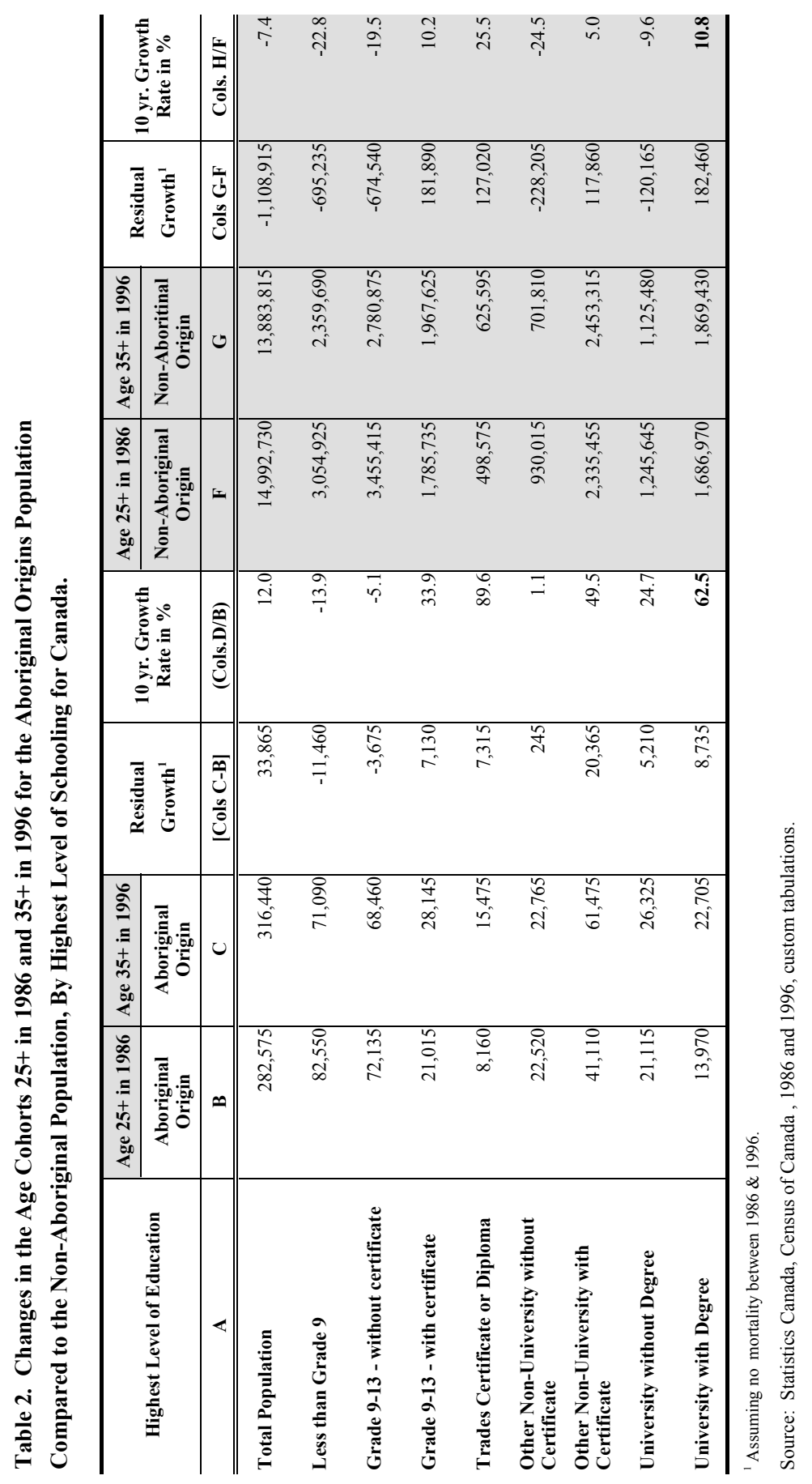


had increased by about 50 per cent or in absolute terms, by over 20,000 and those with university degrees had grown by almost 63 per cent or by nearly 9,000 compared to their respective $25+$ aged cohorts. By contrast, the same age cohorts for the total population showed some positive growth at the higher levels of schooling. The likely reason for the growth at these upper levels of schooling is partly due to the contribution of better-educated international immigrants who tend to be considered favourably during the immigration selection process. (Badets, J. and Howatson-Leo, L., 1999)

Turning to the Aboriginal origin population with and without Aboriginal identity, we find a similar pattern to those with Aboriginal origins, regardless of identity. The cohorts aged 35+ in 1996 are smaller than their counterparts aged $25+$ from 1986 at the lower levels of schooling. When the population cohort with Aboriginal identity is compared to those without Aboriginal identity, some important differences emerge. Even though those with less than incomplete high school declined over the ten years in the same cohort, the actual size of the cohort aged 35+ with Aboriginal identity was much larger in 1996 than its counterpart without Aboriginal identity. Nearly 100,000 persons aged $35+$, or almost $52 \%^{4}$, in Aboriginal identity cohort had less than completed high school compared to only about 40,000 , or $32 \%$, in the non-identity cohort - see Table 3.

By contrast, the Aboriginal identity population cohort aged 35+ with completed post-secondary schooling (both university and non-university levels) in 1996 was much larger than it was at age $25+$, ten years earlier. Those with a university degree grew by over 5,100 or $144 \%$. This would suggest that ethnic mobility and improvement in schooling among those with higher levels of education augmented the ranks of this cohort over the 1986-96 period. What might some of the reasons be for this growth in the size of the same cohorts at the higher levels of schooling?

As pointed out earlier, in 1985 the Indian Act of Canada was amended under Bill C-31. This amendment allowed Indian women (and their subsequent children) who had lost their legal status as an Indian, because they had married men without legal Indian status, to regain their legal Indian status. One of the benefits of being a registered Indians is that it guarantees paid post-secondary schooling. Of the people who applied for reinstatement, many were not granted it. For example, between 1985 and 1991 over 160,000 had applied, but only about 80,000 had received their Indian status at that time. The number regaining Indian status slowed down in the next five years with only another 25,000 being reinstated. (INAC, March, 1998) It is possible that many of those persons seeking legal reinstatement as registered Indians may have begun declaring their Indian ancestry and identity in the census, especially those who may have been eligible for post-secondary funding under the Indian Act. Furthermore, even those who did not meet the requirements for reinstatement also may have begun to declare their Aboriginal ancestry on their census forms and to self-identify as North American Indians in Statistics Canada's 1991 Aboriginal Peoples Survey. Thus, it is probably safe to assume that many of 


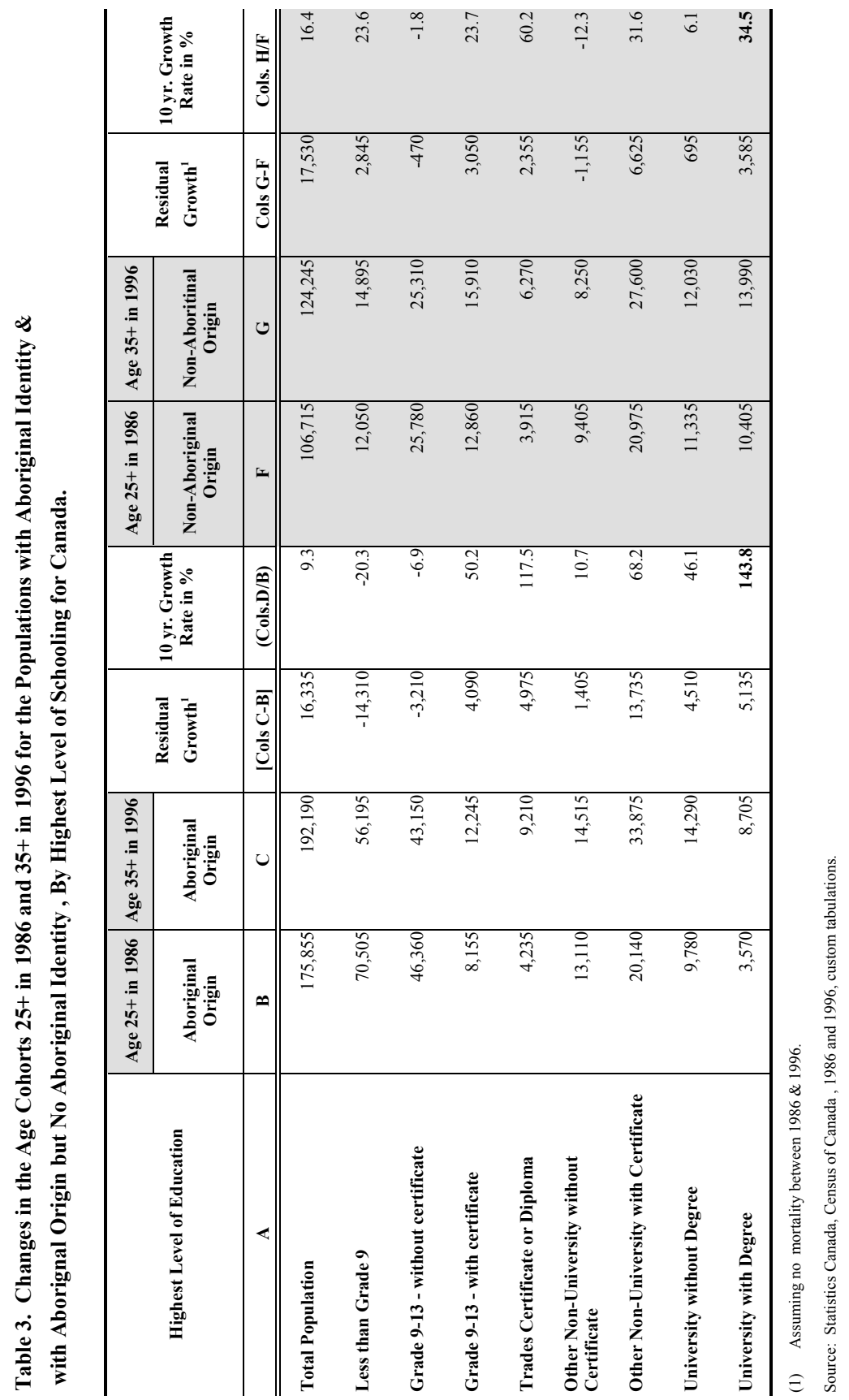


the women and their children, having lived off reserves for many years, already received a post-secondary education. Some of their children may well have been attending post-secondary school during the late 1980s and early 1990s when they decided to seek reinstatement under Bill C-31. This amendment to the Indian Act probably was one of the main factors for the number of Indians in the 25+ age cohort with post-secondary schooling increasing rapidly in the 1986-96 period.

In addition, other consciousness-raising events (e.g.., the 1990 Oka crisis, the First Ministers Conferences on Aboriginal rights between 1985 and 1987) likely have affected disproportionately the growth of the Aboriginal population with post-secondary schooling levels. Based on Escbach's findings, there is every reason to believe that the post-secondary student population would be even more affected by these events, since it is the population with post-secondary schooling who appear to be changing their identity declaration, given the observed growth in the older cohorts. However, without a longitudinal study which tracks how people report their Aboriginality over time and their socioeconomic characteristics, such as their schooling attainment, we are left with providing the above speculations to try and explain the increase in the size of the Aboriginal cohorts by highest levels of schooling.

The puzzle becomes a little clearer when we examine the Aboriginal identity group (Indian, Metis and Inuit) according to what type of origins they report. Here, we begin to control for the effect of ethnic mobility by focusing on specific Aboriginal groups who give:

- the same origin as they do identity (for example, those who give Indian identity and an Indian origin only) which yields three combinations: Indian/Indian, Metis/Metis and Inuit/Inuit, and

- those who give a different Aboriginal origin from their identity group (i.e., those giving an Indian identity and a Metis origin), or give a mixed set of origins (i.e. Indian identity with mixed Indian and non-Aboriginal origins). We classify these combinations as Indian+Other, Metis + Other and Inuit + Other.

All six groups tend to follow the overall pattern of the Aboriginal identity population aged $25+$ in 1986 and $35+$ in 1996 , but there are some important differences. From Table 4, we observe an increase in the cohort with Indian identity and Indian origin (hereafter referred to as the Indian/Indian cohort) among those with completed post-secondary schooling. Again, part of this increase is likely due to improvements in educational attainment within the age cohort where some of it could be coming from the Bill C-31 women and their children who gained Indian status who may not have been declaring their Indian identity in the past and who already have higher levels of schooling. What is interesting to note, however, is the total Indian/Indian age cohort $25+$ in 1986 and 35+ in 1996 actually declined by about $8 \%$ over the ten years. This could be due to mortality and possibly net out ethnic mobility. The sharp distinction occurs with the Indian + Other group where the growth in the cohort between 


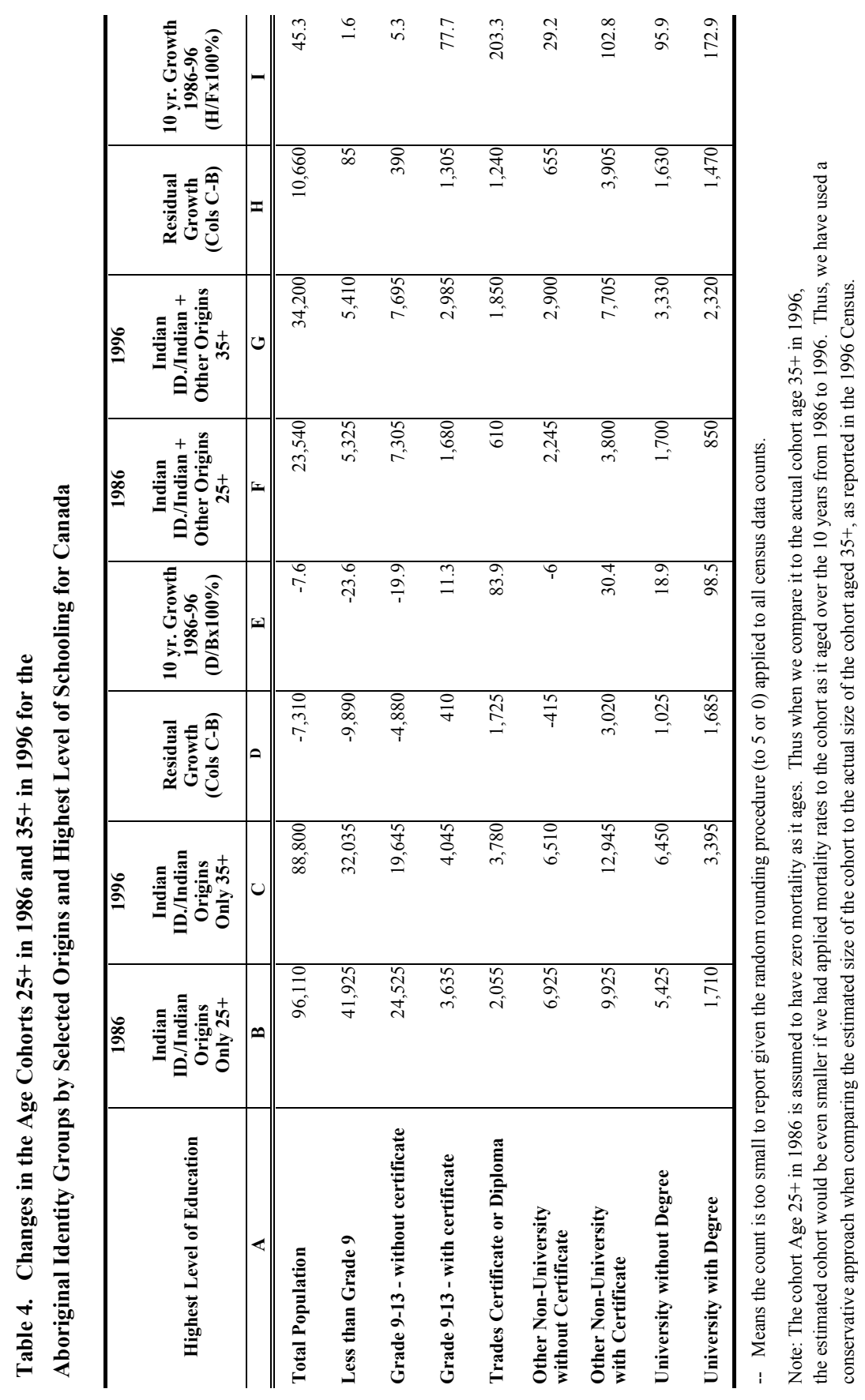




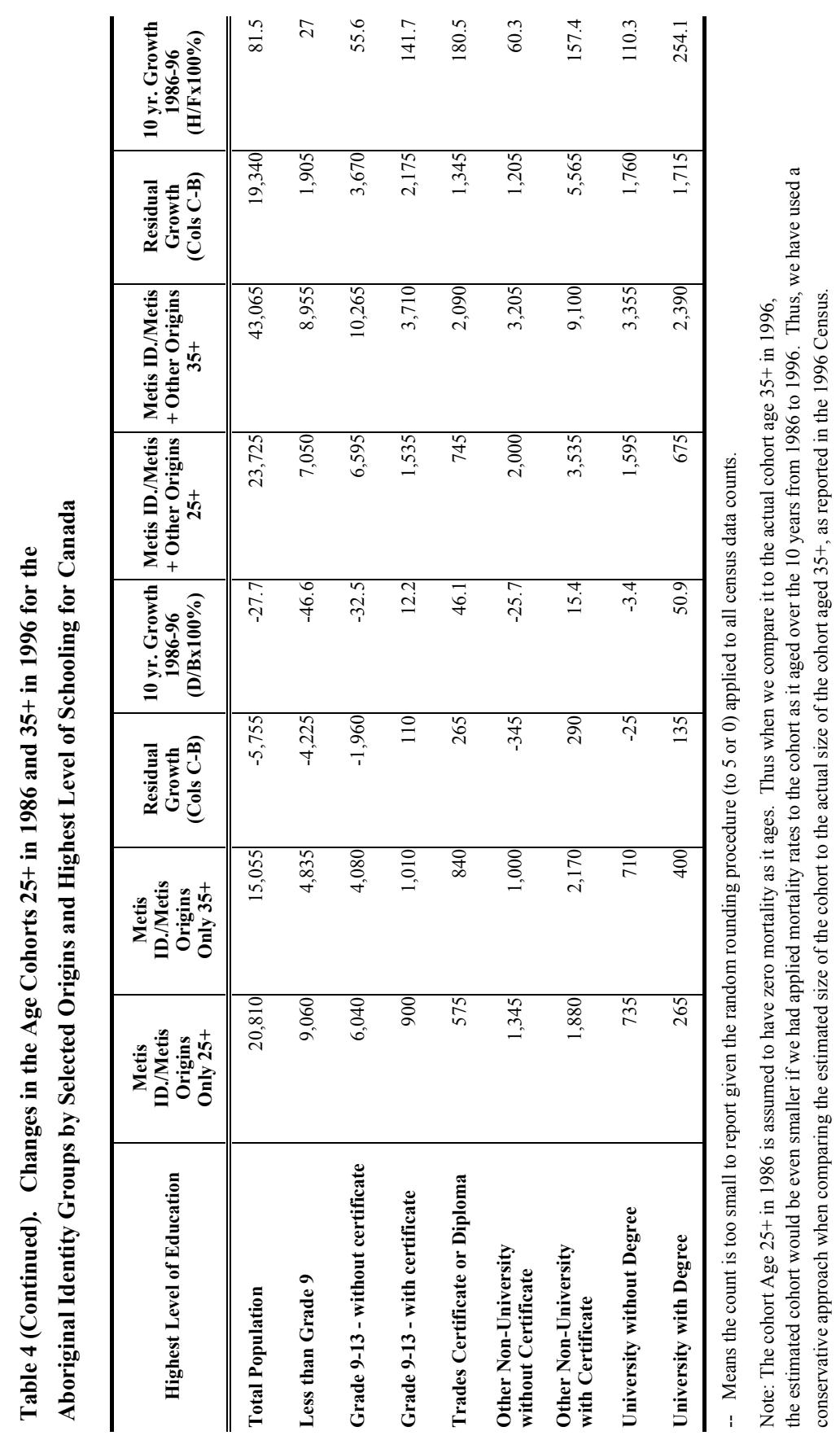




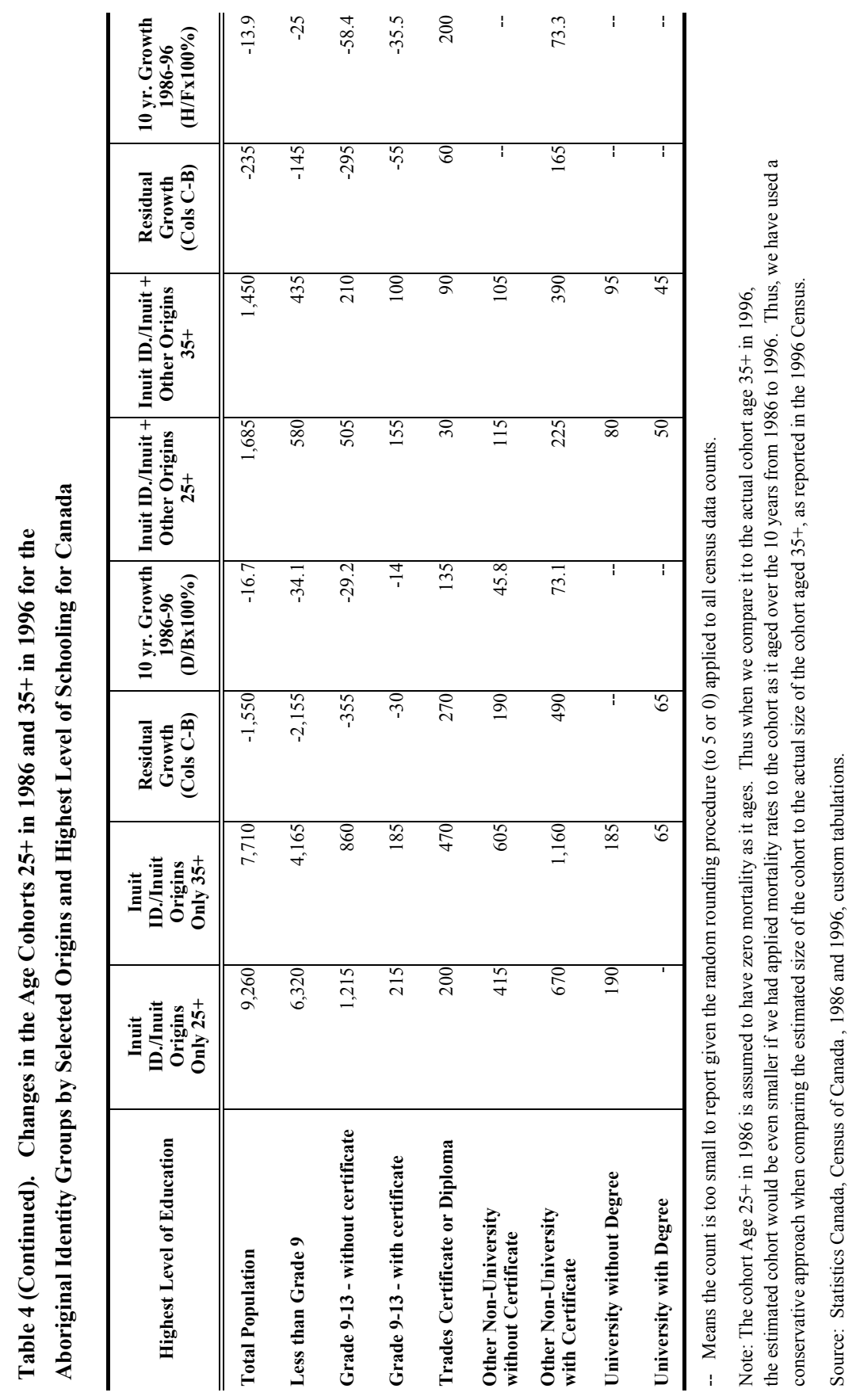


1986 and 1996 is much stronger than their Indian/Indian counterparts. The Indian+Other group with non-university certificates saw its cohort double in size and those with a university degree nearly triple - see Table 4.

For the Metis/Metis group, like their Indian/Indian counterparts the overall cohort $35+$ declined in size relative to its $25+$ cohort. However, the cohort with post-secondary completions saw modest increases of $15 \%$ for the non-university completions and about $51 \%$ for the university completions. On the other hand, the Metis+Other cohort saw its numbers with university completions nearly quadruple. This increase was even greater than the cohort reporting Indian + Other origins.

The numbers for the Inuit population are quite small, especially for those with university degrees, and one must be extremely careful in interpreting the results. Nevertheless, as in the other Aboriginal groups, we see the same general pattern over the cohorts for most levels of schooling.

\section{Summary}

This study has attempted to demonstrate that the contribution which ethnic mobility has made to the overall rapid population growth of Aboriginal peoples between 1986 and 1996 also has implications for the socio-economic characteristics of aggregate Aboriginal populations. This component of demographic growth begs the following question. Are the socio-economic characteristics of the ethnically mobile population, who have apparently joined the ranks of the Aboriginal population over the last 10 years, the same or different from those who have consistently declared their Aboriginality over that time period?

Using a modified version of an approach by Eschbach et al applied to U.S. Census data for the American Indian population, we have shown that for the Aboriginal populations in Canada there, indeed, has been an upward shift in the education attainment distribution of the same age cohort over time. The period we adopt is the 1986-96 period because we have data on the population by Aboriginal origins and Aboriginal identity. The results clearly show that the same cohort, those aged 25+ years old in 1986 and 35+ years old in 1996 increased their absolute numbers and their share of those with post-secondary school completion (at the post-secondary non-university and university levels).

The population in this cohort should have declined due to the following factors: 1) the impact of mortality, 2) had their been no improvement in the education level of the original cohort aged $25+$ over the time period and 3) if no net ethnic mobility had occurred. What we found was that there was an upward shift in the numbers and share of those with higher levels of schooling among the following: 
Andrew J. Siggner

- the Aboriginal origin population,

- among those who have Aboriginal origins and self-identify as Aboriginal, and

- among those with Aboriginal origins those who do not identify as Aboriginal.

Within specific Aboriginal groups, this improvement is more evident among those who identify as Aboriginal, but who have different origins from their Aboriginal identity group. The ten-year increase was most prevalent in our socalled Metis+Other group whose cohort aged 35+ in 1996 with a university degree nearly quadrupled in size relative to the same cohort when it was ten years younger in 1986. As there are less directed government programs which sponsor post-secondary schooling for Metis, as compared to the Indian population, this observation suggests that there has likely been a net inflow of persons declaring themselves as Metis who are well-educated. The same is true for Indian identity population and, in particular, the Indian+Other group. Some of this growth may have been due to the impacts of the Indian Act amendment, Bill C-31, which allowed Indians who lost their legal Indian status to be reinstated. It also allowed their children to become eligible for post-secondary school funding under the Indian Act. This amendment may also have served as an incentive for people who thought they might be eligible to start declaring their Indian identity, where, for any number of reasons before 1985, they did not acknowledge it.

\section{Acknowledgements:}

The author wishes to acknowledge Eric Guimond of Indian and Northern Affairs Canada, Gustave Goldmann and Doug Norris and Janet hagey of Statistics Canada, Norbert Robitaille of the Université du Montréal, for their relevant and generous comments and input to this study.

Notes:

1. The reader will recall that the actual cohort in 1996 does experience mortality, but in our original cohort we assume that mortality is zero.

2. The sum of those with less than Grade $9(29.2 \%)$ and some high school $(22.5 \%)$ - see Table 1 . 


\section{End Notes:}

1. Eschbach et al actually refer to the concept of "racial identity" in their study based on U.S. Census data, but we have chosen to use the term, ethnic identity or origin, to reflect the terminology that is more relevant to Canada.

2. Unlike the Eschbach approach in which survival rates were applied to their earlier cohort, we have not applied mortality rates to the population aged $25+$ and survived them to 1996 when they would be $35+$. Had we done so, the gap between the survived population and actual population would be wider than is observed, especially for those with higher levels of schooling.

3. The reader will recall that the actual cohort in 1996 does experience mortality, but in our original cohort we assume mortality is zero.

4. The sum of those with less than Grade 9 (29.2\%) and some high school (22.5\%) - see Table 10.3)

\section{References:}

Badets, J., and Howatson-Leo, L., "Recent Immigrants in the Labour Force," in Canadian Social Trends, Statistics Canada, Spring Issue, 1999.

Catalogue No. 11-008.

Canada. Royal Commission on Aboriginal Peoples, Report of the Royal Commission on Aboriginal Peoples, Canada Communications Group, Ottawa, 1996. Catalogue No. Z1-1991-1E, Volume 1, Chapter 2, p.15)

Eschbach, K., Supple, K., and Snipp, M., "Changes in racial identification and the educational attainment of American indians, 1970-1990," in Demography, Vol.35, No. 1, February 1998: 35-44.

Guimond, E., "Ethnic Mobility and the Demographic Growth of Canada's Aboriginal Populations from 1986 to 1996," in Current Demographic Trends, December, 1999.

Kreager, P., "Population and Identity,", in Anthropological Demography: Toward a New Synthesis, edited by D. Kertzer and T. Fricke, University of Chicago Press, Chicago, 1997. p. 148.

Nault, F., Roberge, R., et Berthelot, J.-M., "Espèrance de vie et espérance de vie en santé selon le sexe, l'état matrimonial et le statut socioéconomique au Canada," en Cahiers québecois de démographie, Vol.25, no 2 , automne, 1996 , pp. 24-25. 
Andrew J. Siggner

Tait, H., "Educational Achievement of Young Aboriginal Adults," in Canadian Social Trends, Statistics Canada, Spring Issue, 1999, Catalogue No. 11-008.

Statistics Canada, The Daily, April 14, 1998, Catalogue No. 11-001E. 